The Budget Process and the Size of the Budget

Author(s): John Ferejohn and Keith Krehbiel

Source: American Journal of Political Science, Vol. 31, No. 2 (May, 1987), pp. 296-320

Published by: Midwest Political Science Association

Stable URL: http://www.jstor.org/stable/2111078

Accessed: 15-09-2017 21:56 UTC

JSTOR is a not-for-profit service that helps scholars, researchers, and students discover, use, and build upon a wide range of content in a trusted digital archive. We use information technology and tools to increase productivity and facilitate new forms of scholarship. For more information about JSTOR, please contact support@jstor.org.

Your use of the JSTOR archive indicates your acceptance of the Terms \& Conditions of Use, available at http://about.jstor.org/terms extend access to American Journal of Political Science 


\title{
The Budget Process and the Size of the Budget
}

\author{
John Ferejohn, Stanford University \\ Keith Krehbiel, Stanford University
}

The new congressional budget process provides members of Congress with a new set of institutional mechanisms for making budget decisions. This article addresses the question of whether or under what conditions rigid application of the new budget process (modeled as, first, selection of the size of the budget and, second, its division) produces smaller budgets than a piecemeal appropriations process in which the size of the budget is determined residually. The theoretical result is that the new process sometimes results in relatively large budgets. A testable implication of the theory is that given a choice of how stringently the budget process is to be employed, members of Congress jointly consider preferences and the expected outcomes under available institutional arrangements and select the arrangement (usually a rule) that yields the most favorable outcome. Empirical results from the budget process in the House from 1980 to 1983 are generally supportive of the theoretically derived hypothesis of rational choice of institutional arrangements.

In 1974 Congress adopted a new process for making budget decisions. Instead of considering appropriations requests one at a time and letting the overall level of spending be determined residually, the 1974 Budget and Impoundment Control Act (PL 93-344) required Congress to enact a budget resolution that set overall spending levels and then instructed authorizations and appropriations committees to keep within those levels when writing their separate bills. A key purpose of the act was to encourage Congress to consider explicitly questions of fiscal policy and to make trade-offs when setting spending levels for individual programs.

Many of the proponents of the act believed that the budget process would lead to a lower level of spending than would otherwise occur. Their argument was that each member of Congress has programs in which he or she is especially interested and consequently attempts to expand through generous appropriations. But the sequential expansion of many programs ultimately leads to an overall level of spending that is higher than a majority would choose if the size of the budget were voted upon initially and directly. In other words, there was a widespread belief that everyone (or at least a majority of both houses) would prefer a lower budget level and correspondingly lower funding levels for individual programs than that which results from the piecemeal nature of pre-1974 budgetary politics. This reasoning enticed fiscal conservatives to crusade for budgetary reforms. With the assistance of liberals, who were 
increasingly disillusioned with President Nixon's aggressive use of impoundments, reforms were passed almost unanimously. ${ }^{1}$

While the major reason for the overwhelming support for the act is a matter of some dispute (Schick, 1980), there is no doubt that the debate surrounding its passage contains numerous references to its desirability as a tool to control budgetary growth (Fisher, 1985). But recent events, such as the dramatic increase in deficits and a persistent inability or unwillingness of either the Congress or the president to take correspondingly strong action, provide a basis for questioning the effectiveness of the 1974 budget reforms. There is no strong evidence for the proposition that the act has controlled spending. Rather, there is merely the argument that without the 1974 act, things would have been worse; levels of spending would have been higher and deficits larger.

But determining whether the new budget process has achieved the goal of controlling expenditures, relative to an appropriate alternative such as the old appropriations process, is a difficult task. As Shepsle (1984) notes, "the appropriate experiments cannot be run." 2 Furthermore, while we cannot experiment with Congress, Congress, nevertheless, does annual experiments itself by choosing which of a variety of budgetary institutional arrangements to employ. These twin complexities are addressed below by substituting a formal theory for the inability to experiment and, then, using the annual congressional choices of institutional arrangements as sources of data suitable for testing the theory. Two models are developed and analyzed: a budget process and an appropriations process. In the model of the budget process, which resembles post-1974 decision making when the budget act is most rigidly applied, the first decision is on the size of the budget, and subsequent decisions are on levels of individual appropriations within the budget constraint. In the contrasting model of the appropriations process, which resembles pre-1974 budgeting or post-1974 weak applications of the budget act, appropriations decisions are made first, and the size of the budget is determined residually. The theory on which these models are based provides an answer to the question of whether and when a budget process results in smaller budgets than an appropriations process. The endogeneity of institutional features associated with congressional budgeting makes it possible to test the theory by interpreting roll call votes on procedural questions as revealed preferences for or against processes resembling one of the two stylized models.

${ }^{1}$ The final votes in the House and Senate were 401-6 and 75-0.

${ }^{2}$ Others are similarly cognizant of this difficulty (see, e.g., Schick, 1980; LeLoup, 1980; Ellwood, 1983; Copeland, 1984; Shepsle, 1984; and Fisher, 1985). 


\section{A Theory of Congressional Budgeting}

We have only one history, of course, and in that history Congress passed the 1974 Budget and Impoundment Act. Although the new budget process was not immediately revolutionary, a new set of institutions and procedures emerged that can make congressional budgeting under the act significantly different from the old appropriations process. One such procedure is reconciliation. ${ }^{3}$ When included in the first budget resolution and rigidly adhered to, reconciliation has the practical effect of making that resolution binding, thus constraining subsequent appropriations decision making. While perhaps not subscribed to universally, this view of reconciliation is increasingly orthodox. ${ }^{4}$ Ellwood (1984), for example, writes that

by grouping a series of reductions into a single bill, [the reconciliation process] gives greater power to the aggregates (the "budget line"). The political debate can be shifted from the parts to the whole, particularly when the party leadership (at least in the House) obtains a limited or closed rule for the bill.

(p. 377)

Thus, not only reconciliation but also relatively closed amendment procedures (as defined by special rules in the House) affect the degree to which the first-stage decision on the size of the budget is binding.

Given a primary interest in the relative budget sizes that result from two different institutional arrangements but a concomitant inability to experiment with Congress, a convincing theory of budgeting is needed to predict budget sizes. Although the proposed versions of the old piecemeal appropriations process and the new budget process are stylized, they are nevertheless consistent with many descriptive accounts of old versus new forms of budgeting. ${ }^{5}$ Each is a special case of a general theory that is consistent with two intuitions about Congress. First, in each model, decision making occurs sequentially. The piecemeal appropriations process, which was prevalent before 1974, involved consideration of appropriations requests one at a time with the size of the budget determined ex post by summing the budget outlays granted in the separate

\footnotetext{
${ }^{3}$ The strategic considerations surrounding the highly publicized reconciliation procedure of 1981 are described in Miller and Range (1983) and LeLoup (1982). For histories of reconciliation before and since 1981, see Fisher (1985), Gilmour (1985), Reischauer (1984), and Schick (1981).

${ }^{4}$ Additional support can be found in Collender (1983) and Gilmour (1985). For a possible dissent-or at minimum a persuasive argument that the new budget process has loopholes in spite of reconciliation-see Fisher $(1984,1985)$.

${ }^{5}$ See, e.g., Ellwood's (1983) "fragmented" and "comprehensive" approaches or Bozeman and Straussman's (1982) "bottom-up" versus "top-down" processes.
} 
appropriations bills. In contrast, when the new budget process is rigidly applied, a binding first budget resolution sets the size of the budget ex ante. Then appropriations bills are considered sequentially as in the appropriations process, except that the budget constraint is known.

A second feature of the general theory shared by the two specific models is that actors are sophisticated. Specifically, their votes at any given stage are influenced by others' preferences and by the consequences of the present choice on future choices. For example, in deciding on the first appropriations bill in a session, members do not ignore the fact that appropriating huge sums of money on current appropriations bills leaves less money for subsequent appropriations. Nor do they ignore what other members are likely to do, given their preferences and foresight.

Ultimately, the theory enables prediction not only of individuals' behavior at given stages of the process but also of aggregate outcomes, that is, the size of the budget and the mix of appropriations to various programs. The theoretical finding contradicts the charges of disillusioned Democrats in 1981 as well as most conventional accounts of the effects of a stringently implemented budget process. ${ }^{6}$ In short, a strict budget process does not necessarily lead to smaller budgets than would have been produced by a process without a binding first resolution. Rather, the size of the budget depends on characterizable features of the preferences of legislators.

\section{The General Theory}

Assume that there are two dollar-denominated activities with which the legislature is concerned: military spending and domestic spending. Thus, any budgetary decision can be represented as a point in a twodimensional space. Total public-sector spending is simply equal to military plus domestic spending. Any point in the space implicitly represents a size of the budget in addition to a division of the budget between categories of expenditure. Legislators are assumed to have Euclidean preferences over the space of policy alternatives (i.e., circular indifference curves in the two-dimensional space). Thus, each member, $i$, has a most preferred point, $x_{i}^{*}$. For any two alternatives, $y$ and $z$, a member prefers $y$ to $z$ if and only if the distance from $x_{i}^{*}$ to $y$ is less than the distance from $x_{i}^{*}$ to $z$. With this assumption about preferences, the members' preferences are completely described by their ideal points.

A number of characteristics of this theory are well known. For example, unless extremely restrictive assumptions are made about the

\footnotetext{
${ }^{6}$ An important exception is Ellwood (1984), to whose work we shall return in the discussion.
} 
distribution of the ideal points, there is no pure majority rule equilibrium. However, if choice is restricted to a one-dimensional subset of the space, preferences on this subset are single-peaked, and there is a unique majority rule equilibrium on that subset. Two special cases of the general theory are illustrated below. Both exploit the foresight of actors which, in essence, constrains choice to a single dimension.

\section{Model A: The Appropriations Process}

Suppose that the legislature makes its allocative decision by breaking the problem into pieces and sequentially deciding on the components. For example, the legislature may decide on the level of military expenditures first and then turn to the question of domestic spending, thus determining the total size of the budget. For any particular order of business, members' votes are determined by their anticipation of what happens at the subsequent stage(s), given what happens and happened at the current and prior stage(s).

Consider the three-member legislature in Figure 1 and suppose that member 3 proposes to set military spending at $m_{1}$, which is represented by the horizontal line through his ideal point. Members 1 and 2 examine the implications of a decision of $m_{1}$ at stage 1 for the subsequent decision on the domestic dimension. They are repelled by their expectation that at the second and final stage the median of ideal points projected onto $m_{1}$ would be selected. In contrast, they see that a stage 1 decision of lower military expenditures would bring the outcome closer to their ideal points. Eventually, $m_{2}$ (the median of ideal points projected onto the military dimension) is proposed and accepted at stage 1 , whereupon the median of the ideal points projected onto $m_{2}$ is selected at stage 2 . With an odd number of legislators, this point is always the intersection of medians. Under an institutional arrangement that permits changes on only one dimension at a time, the point is an equilibrium, ${ }^{7}$ henceforth called the appropriations process equilibrium and labeled $A$.

If each member has circular indifference curves, the appropriations process equilibrium does not depend on the order of voting on the appropriations bills. This model is a special case of a model considered by Kramer (1972), who provided sufficient conditions for an equilibrium to be independent of the order of consideration of the bills. As Kramer observed, the equilibrium corresponds exactly to a sophisticated voting outcome. ${ }^{8}$

\footnotetext{
${ }^{7}$ Notice that at the equilibrium $(A)$ in Figure 1, any proposal in either a horizontal or vertical direction (but not both) fails to receive a majority of votes.

${ }^{8}$ The existence of such equilibria may be proved under much more general circumstances. If the members have strictly convex preferences, then, for any particular and
} 
FIGURE 1

Equilibrium in the Piecemeal Appropriations Process

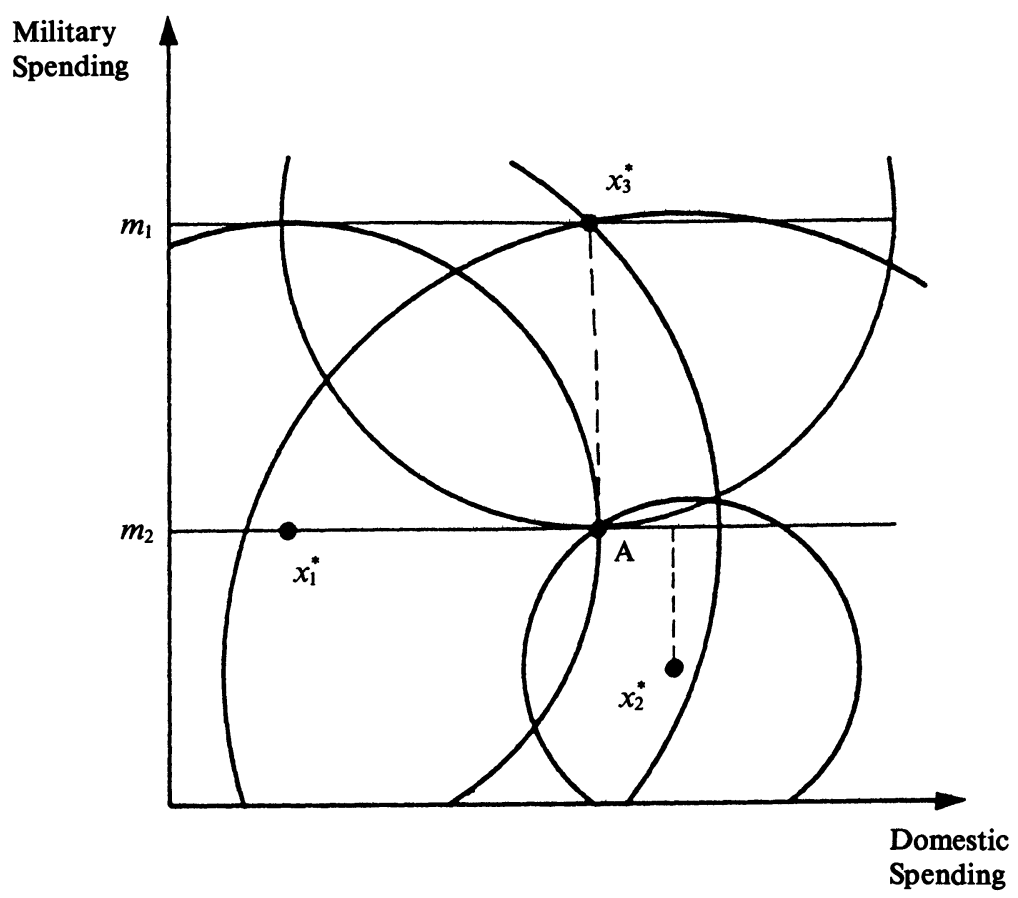

\section{Model B: The Budget Process}

Suppose that instead of considering appropriations bills immediately, members initially take up the question of the size of the budget, after which they decide on the allocation of resources for domestic and military purposes. Given a particular size of the budget (represented in two dimensions by a 45-degree line), the allocation question becomes one-dimensional and therefore has a unique majority rule equilibrium. This allows members to choose the size of the budget, conditioned

commonly known ordering of bills for consideration, there will be an equilibrium. But since the location of the equilibrium depends on the order of consideration-something that might not be known by all members in advance-calculation of voting strategies by members is impeded. For that reason we focus on a model with circular preferences rather than one in which members know the order of consideration of appropriations bills. We return to this assumption in the final section. 
by their expectations of what mix of military and domestic appropriations results from different budget sizes. This process is illustrated in Figure 2.

The key to showing the existence and finding the location of the budget process equilibrium is that any given budget size has an associated outcome. For example, if $b_{1}$ were the budget size selected at stage 1 , then subsequent decision making yields the mix of domestic and military spending represented by $O_{1}$, which is the median of ideal points projected onto the $b_{1}$ budget line. For similar reasons, budget sizes $b_{2}$ and $b_{3}$ have associated outcomes of $\mathrm{O}_{2}$ and $\mathrm{O}_{3}$, respectively. Since members of Congress are assumed to be sophisticated, they do not select a budget size without anticipating the consequences of that first choice on subsequent choices about how the budget is to be divided. Thus, $b_{1}$ is

\section{FIGURE 2}

Equilibrium in the Budget Process

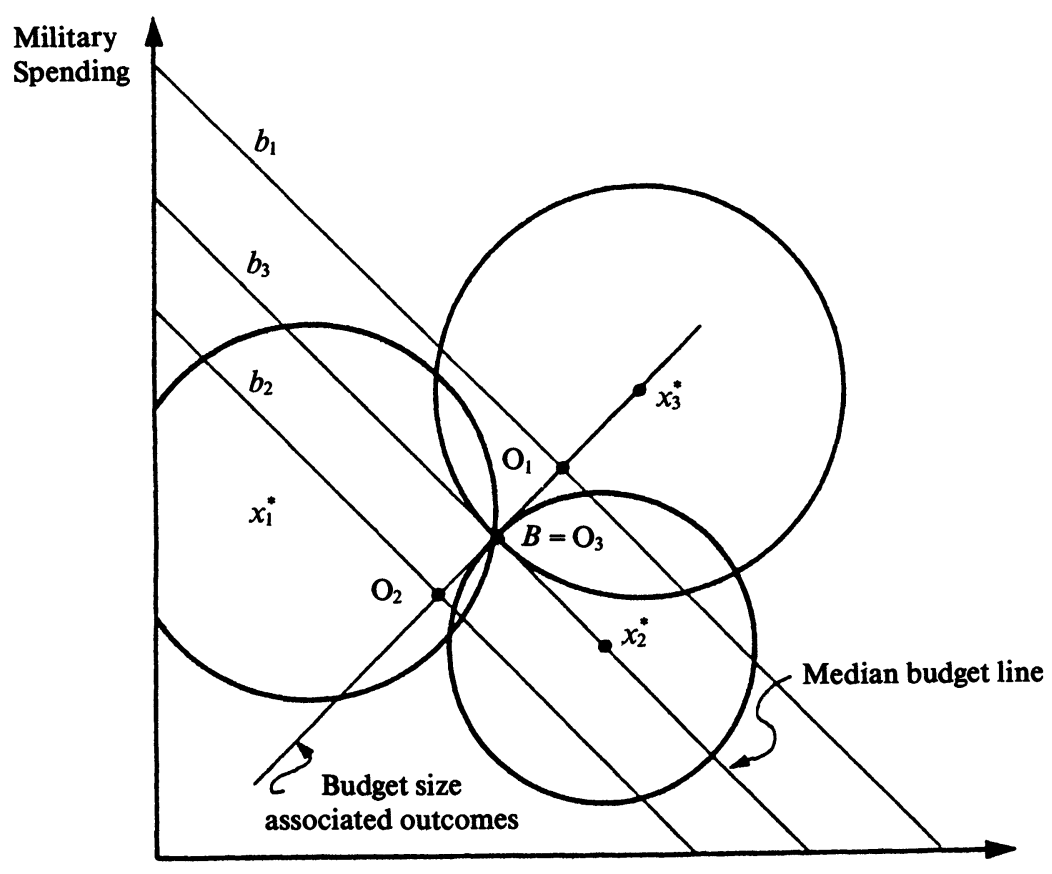

Domestic Spending 
not a first-stage choice because members 1 and 2 prefer outcomes associated with smaller budget sizes. Nor is $b_{2}$ chosen because members 2 and 3 prefer outcomes associated with larger budget sizes. Clearly, if there is an equilibrium under the specified conditions, the point must be in the set of budget size associated outcomes and must not be preferred by a majority to any other point in the set. In Figure 2 the set of budget associated outcomes is represented by the line perpendicular to the budget lines and passing through the ideal point of the median voter (member 3) with respect to the budget lines. A projection of ideal points onto the line of budget associated outcomes reveals legislator 2 as the median voter in this one-dimensional subspace. The point $O_{3}$ therefore uniquely meets the specified conditions and is a budget process equilibrium, $B$.

Existence of equilibria in both models permits answering the question of whether the size of the budget is always smaller under the budget process than under the appropriations process. Figure 3 shows that no general relationship exists. In Figure 3.A, conventional wisdom is confirmed; total expenditures under the budget process $(B)$ are exceeded by total expenditures under the appropriations process $(A)$. However, when the configuration of ideal points is altered, as in Figure 3.B, the budget process produces the opposite outcome-larger expenditures than under the appropriations process.

The analysis thus far establishes not only that institutional arrangements make a difference in budgeting outcomes but, more specifically, that the difference they make depends on the configuration of preferences of actors. The final theoretical task is to characterize configurations of preferences that do and do not make the budget process an institutional arrangement that reduces the size of the budget. (We continue to focus on two dimensions of expenditure, even though the result can be generalized.)

For convenience of exposition, assume that the legislature is large enough so that the distribution of members' ideal points can be described by a probability measure, $\mu$, that possesses a density function, $f$. Then the proportion of ideal points in a set of points, $P$, may be written $\mu(P)$ which equals $\int_{P} f(x) d x$. First, normalize expenditures so that the appropriations equilibrium (point $A$ ) is the origin. Now define the following sets of points that partition the space as illustrated in Figure 4.

$$
\begin{aligned}
& P=\left\{x: x_{1}+x_{2} \geqslant 0 \text { and } x_{1} \leqslant 0\right\} \\
& Q=\left\{x: x_{1}+x_{2} \leqslant 0 \text { and } x_{2} \geqslant 0\right\} \\
& R=\left\{x: x_{1} \leqslant 0 \text { and } x_{2} \leqslant 0\right\} \\
& S=\left\{x: x_{1}+x_{2} \leqslant 0 \text { and } x_{1} \geqslant 0\right\} \\
& T=\left\{x: x_{1}+x_{2} \geqslant 0 \text { and } x_{2} \leqslant 0\right\} \\
& U=\left\{x: x_{1} \geqslant 0 \text { and } x_{2} \geqslant 0\right\}
\end{aligned}
$$




\section{FIGURE 3}

The Budget Process and the Size of the Budget

A. Budget process results in a smaller budget.

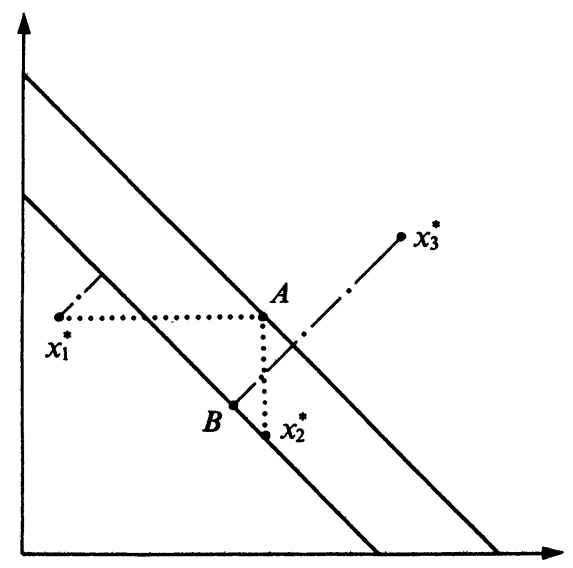

B. Budget process results in a larger budget.

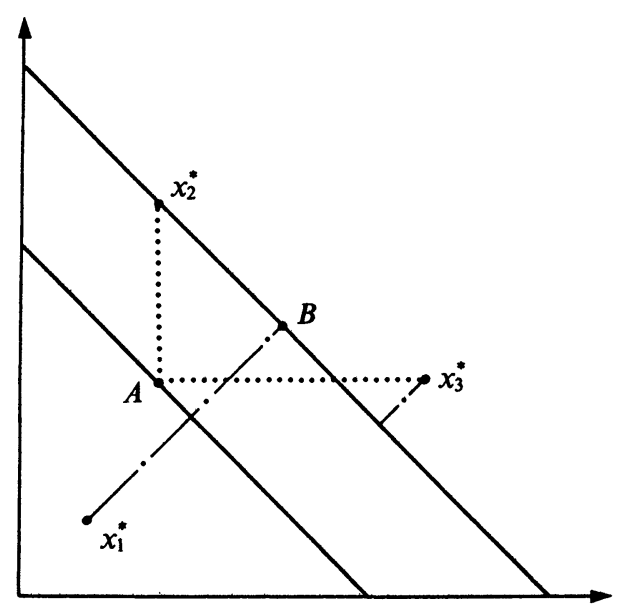

KEY:

Budget lines

- - Projections onto median budget line

....... Projections of military and domestic medians onto point of intersection (A) 
FIGURE 4

Regions in the $\mathrm{D} \times \mathrm{M}$ Plane

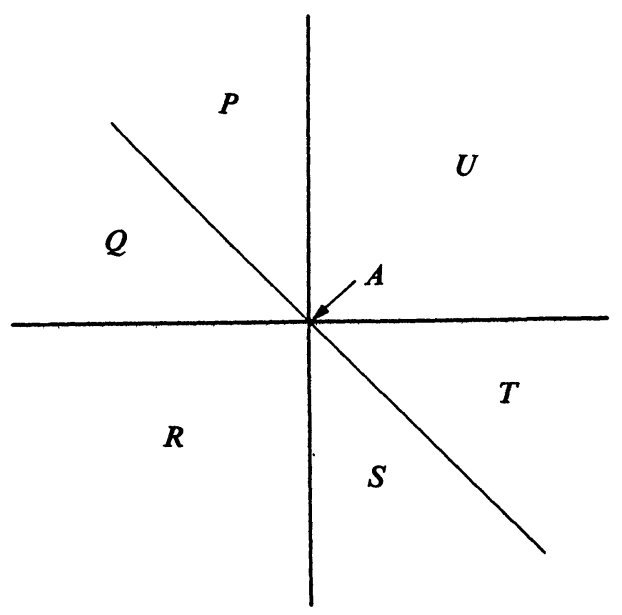

Since the appropriations process equilibrium is the intersection of medians and the budget process is the intersection of medians of ideal points that have been projected onto the axes rotated 45 degrees, the following proposition can be easily demonstrated.

LEMMA: The budget process equilibrium, $B$, has a budget size larger than that of the appropriations equilibrium, $A$, if and only if $\mu(P)+\mu(U)+\mu(T)>1 / 2$.

Necessary and sufficient conditions for the budget process to increase the size of the budget follow.

THEOREM: The budget size of the budget process equilibrium, $B$, exceeds the budget size of the appropriations equilibrium, $A$, if and only if $\mu(P)>\mu(S)$ and $\mu(T)>\mu(Q)$.

PROOF: First note that because $A$ is the intersection of medians,

$$
\begin{aligned}
& \mu(P)+\mu(Q)+\mu(R)=\mu(S)+\mu(T)+\mu(U)= \\
& \mu(Q)+\mu(P)+\mu(U)=\mu(R)+\mu(S)+\mu(T),
\end{aligned}
$$


and, by substitution, that opposite quadrants are equal:

$$
\begin{aligned}
\mu(P)+\mu(Q) & =\mu(S)+\mu(T), \text { and } \\
\mu(R) & =\mu(U) .
\end{aligned}
$$

For sufficiency, begin with the conditions and simply note that

$$
\begin{aligned}
& \mu(P)>\mu(S) \text { and } \mu(T)>\mu(Q) \Rightarrow \\
& \mu(P)+\mu(T)>\mu(Q)+\mu(S) \Rightarrow \\
& \mu(P)+\mu(U)+\mu(T)>1 / 2>\mu(Q)+\mu(R)+\mu(S),
\end{aligned}
$$

which, by the lemma, implies that the budget size under the budget process exceeds that of the appropriations process. For necessity, begin with an inequality implied by the lemma:

$$
\begin{aligned}
& \mu(P)+\mu(U)+\mu(T)>1 / 2>\mu(Q)+\mu(R)+\mu(S) \Rightarrow \\
& \mu(P)+\mu(T)>\mu(Q)+\mu(S) .
\end{aligned}
$$

Now, using $\mu(P)+\mu(Q)=\mu(S)+\mu(T)$, substitute $\mu(S)+\mu(T)-\mu(Q)$ for $\mu(P)$ :

$$
\begin{aligned}
\mu(S)+\mu(T)-\mu(Q)+\mu(T) & >\mu(Q)+\mu(S) \Rightarrow \\
2 \mu(T) & >2 \mu(Q) \Rightarrow \\
\mu(T) & >\mu(Q) .
\end{aligned}
$$

A parallel argument yields $\mu(P)>\mu(S)$ and establishes necessity. QED.

Figure 4 helps illuminate the political substance that underlies the result. Theoretically, a heavy concentration of ideal points in regions $P$ and $T$, relative to regions $S$ and $Q$, respectively, means that the budget process has the somewhat counterintuitive effect of increasing the budget. The political translation, although somewhat cumbersome, is nonetheless meaningful. Notice first that members in $P$ and $T$ are differentiated from members in $S$ and $Q$ in terms of whether their desires for increases in expenditures in one area exceed their desires for decreases in the other (relative to the origin after normalization). Accordingly, the theorem has the interpretation that implementation of a strict budget process results in a relatively large budget if and only if the number of strong-hawk/moderate-domestic-conservatives $(P)$ exceeds the number of moderate-domestic-liberal/strong-doves $(S)$ and the number of strong-domestic-liberal/moderate-doves $(T)$ exceeds the number of moderate-hawk/strong-domestic-conservatives $(Q)$. In such circumstances an implicit agreement is made to increase the overall level of spending. Indeed, many explanations of the persistence of high deficits are consistent with this translation of the formal argument.

Yet the theory is noncooperative. There is no assumption that a backroom bargain takes place that results in relatively high levels of 
spending under the budget process. The rules of the chambers do not permit members to make binding commitments across votes, so explicit mutually beneficial transactions cannot be made. Indeed, the absence of a pure majority rule equilibrium implies that without the imposition of institutional structure, opportunities and incentives for some majority to improve its welfare would always exist. Therefore, whatever bargains occur must be implicit and must take place in such a fashion that it is in the interest of each party to execute his/her part of the agreement at the appropriate moment.

\section{A Test of the Theory}

An ideal test of the theory would consist of estimating each individual's ideal point in a 16-dimensional space (one dimension for each of the functional categories in the budget resolution), ${ }^{9}$ calculating the budget process equilibrium as a 16-tuple of dollar values, observing the outcome of the budget process in the form of congressional appropriations, and finally assessing how close the predicted outcome is to the observed outcome. Obviously, this is not possible. A few of the many prohibitive obstacles deserve mention. First, the ideal test requires estimation techniques that have not been developed, namely, the identification of ideal points for each member, stated in dollar values. Second, the functional categories of the budget resolution do not correspond precisely with the subsequent appropriations bills. Moreover, Congress typically fails to pass at least a few such bills. And third, since Congress does not repeat the budget processes in a given year under different institutional arrangements, at most one model per year can be tested directly, and even then there are no straightforward criteria for determining what a good or close prediction is.

In spite of these difficulties, the theory is not to be dismissed as untestable. Rather, an indirect test is devised that, at minimum, provides an opportunity to reject the theory. The test exploits the fact that, in four consecutive years beginning in 1980, the House made an observable choice about the form of its budget process to implement. While the House's menu of institutional arrangements does not include our pure forms of budgeting, the arrangements, nevertheless, approximate one model or the other. For the annual budget cycles in the House from 1980 to 1983 , two related questions are addressed by focusing on the House's choice of procedures. First, how binding is the budget line set by the first resolution? Second, how easy is it for members to make piecemeal adjustments in appropriations amounts? In general, to the degree that the rules

\footnotetext{
${ }^{9}$ The number of functional categories has varied over the years (see Fisher, 1985, p. 20).
} 
for amendments or other institutional features employed strengthen the first resolution and restrict members' opportunities to adjust appropriations amounts, the process approximates the model of the pure budget process. Conversely, nonbinding first resolutions and/or provisions for modifying appropriations are indicative of a process more akin to piecemeal appropriations. The most straightforward example is 1981 , in which the key procedural vote was explicitly about consideration of the GrammLatta reconciliation bill under either an open or a closed rule. The closed procedure was adopted, and the reconciliation instructions previously incorporated into the budget resolution proved to be genuinely constraining, thus approximating model $B$. Though sometimes less explicit, comparable choices also occurred in other years of the study. The Appendix contains a detailed description of the votes.

The test, therefore, is an analysis of procedural votes. It consists of three steps: estimation of ideal points in a two-dimensional space, computation of the equilibrium outcomes under the two pure models, and assessment of the degree to which votes on procedures are consistent with various hypotheses. The votes predicted by the theory require that members behave as if they know and believe the theory. Individual members of Congress know the consequences of the real-world analogues to the pure appropriations and budget processes, and, given their expectations about the outcomes that would result, their choice of procedures is rational. If a member's ideal point is closer to $A$ than to $B$, the member opposes the procedure that has the effect of making the budget resolution binding, preferring instead to have the opportunity to make piecemeal changes (via amendments) in appropriations and thus implicitly in the overall budget ceiling. If votes are consistent with this hypothesis of rational choice of institutional arrangements, the model will be supported. In contrast, if competing hypotheses predict as well or better throughout the period, then the theory will be rejected.

As depicted in the theory, the three substantive ingredients represented by ideal points are preferences on domestic policy, defense policy, and overall government spending. A relatively simple scaling technique based on three corresponding interest group ratings is employed here. ${ }^{10}$ First, define a vector $x=\left(x_{1}, x_{2}\right)$ in which the first component is the member's League of Women Voters score (based primarily on domestic roll call votes), and the second component is the member's National Security Index (reflecting the degree of prodefense voting as

${ }^{10}$ There is an expanding literature on (and controversies surrounding) measurement of preferences (see, e.g., Carson and Oppenheimer, 1984; Kalt and Zupan, 1984; Kau and Rubin, 1979; and Poole, 1981). 
evaluated by the American Security Council). This vector is then scaled as a function of overall antispending roll call voting behavior, as measured by the National Taxpayer's Union score. The formula for the ideal point is:

$$
x^{*}=[1-(\mathrm{NTU} / 200)] x .
$$

All scores range from zero to 100 ; thus, for example, the most fiscally conservative members $(\mathrm{NTU}=100)$ are scaled back halfway toward the origin, while NTU's "biggest spenders" who score 0 maintain their original values of $x_{1}$ and $x_{2}$.

Given the estimated ideal points, identification of equilibria for the appropriations and budget processes is straightforward. The appropriations process equilibrium $(A)$ is the intersection of medians on the domestic and military dimensions; the budget process equilibrium $(B)$ is the intersection of medians of projected ideal points onto the axes rotated 45 degrees.

The primary interest is in the relative predictive power of five hypotheses. Three of these formally embody individual-level rational choice; the remaining two are representative of conventional and relatively informal accounts of congressional budgeting since 1974 . The hypotheses are:

HYPOTHESIS 1: Rational choice of institutional arrangements. Members consider both the size of the budget and how it is divided. Predictions are determined by the relative distances between a member's ideal point and the institution-associated equilibria, $A$ and $B$, as determined by $H_{1}$ (see Figure 5).

HYPOTHESIS 2: Rational choice of budget size (fiscal liberalismconservatism). Members choose the institutional arrangement according to their preferences on size of the budget (without regard to its division). Predictions are determined by $\mathrm{H}_{2}$, a 45-degree northwest-to-southeast line passing through point $C$ (which is equidistant from $A$ and $B$ ).

HYPOTHESIS 3: Rational choice of budget division (guns-versus-butter liberalism-conservatism). Members choose the institutional arrangement according to their preferences on division of the budget, namely high domestic and low military spending versus high military and low domestic spending. Budget size, however, is not taken into account. Line $\mathrm{H}_{3}$, a 45-degree southwest-to-northeast line passing through $C$, partitions the set of ideal points to determine this prediction.

Hypothesis 4: Conventional wisdom: Party. Republicans (assumed to be more fiscally conservative than Democrats) vote for the strict 


\section{FIGURE 5}

Separating Hyperplanes for Hypotheses 1-3

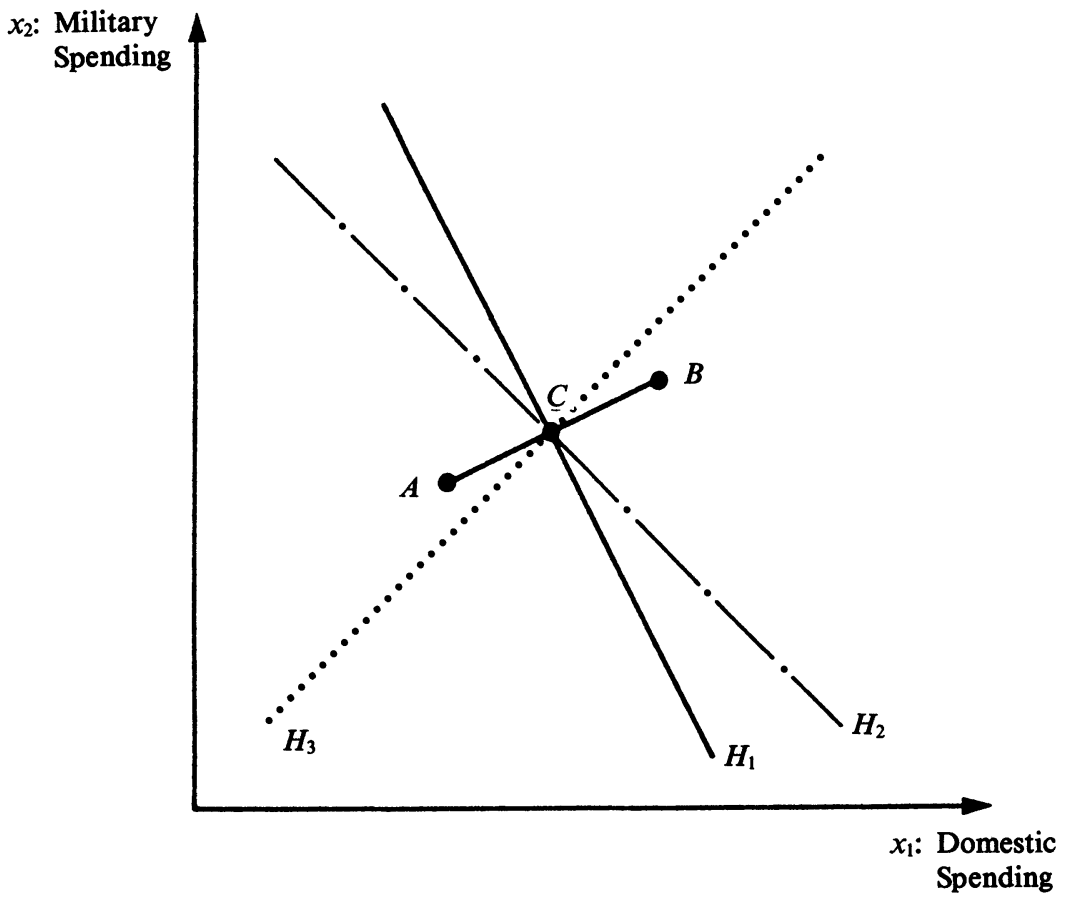

form of the budget process, which they believe results in a smaller budget; Democrats do the opposite.

HYPOTHESIS 5: Conventional wisdom: Party and region. Republicans and Southern Democrats (assumed to be more fiscally conservative than non-Southern Democrats) vote for the strict form of the budget process. Non-Southern Democrats vote for the weaker form which resembles piecemeal appropriations.

Hypotheses 2 and 3 are included as null models, albeit models with some theoretical and spatial foundation. One main empirical question is whether Hypothesis 1 , which jointly considers questions of budget size and budget division, predicts better than the models in which only size or division is considered. Hypotheses 2 and 3, then, can be viewed as constrained versions of our theory. In contrast, Hypotheses 4 and 5 
have no explicit spatial or theoretical basis, but have been proffered by observers of recent cycles of congressional budgeting. The relevant comparison here is not Hypothesis 4 with 5, but rather Hypotheses 4 and 5 with 1. The latter comparisons answer the question of whether an explicit theoretical account of how preferences are expressed in a rich institutional context facilitates prediction of congressional behavior and budgetary outcomes.

\section{Results}

Table 1 presents the percentage of votes correctly predicted by each hypothesis in 1980-83. Overall, Hypothesis 1-rational choice of institutional arrangements - predicts best. Next in overall performance are Hypotheses 3 and 2, the restricted versions of our theory. Finally, the hypotheses based on regularities in party voting and in party-region coalition formation have the worst overall records, dropping below 50 percent for the four-year period. The bottom line, then, supports the generalization that the more information a theory explicitly incorporates about individual preferences, the better it predicts endogenous institutional choices.

Inasmuch as the bottom line fails to convey the whole story, it is useful to look more closely at individual years, as summarized in Figure 6. Consider the year in which the conventional wisdom hypotheses perform best and on which (understandably) much of conventional wisdom is

\section{TABLE 1}

Percentage of Votes Correctly Predicted by the Five Hypotheses

\begin{tabular}{|c|c|c|c|c|c|c|c|c|}
\hline \multirow[b]{2}{*}{ Year } & \multirow[b]{2}{*}{$N$} & \multicolumn{2}{|c|}{ Coordinates of Equilibria } & \multicolumn{5}{|c|}{ Hypotheses* } \\
\hline & & Appropriations & Budget & 1 & 2 & 3 & 4 & 5 \\
\hline 1980 & 421 & $(39.0,42.8)$ & $(39.7,42.2)$ & 76.5 & 62.7 & 76.7 & 3.8 & 20.1 \\
\hline 1981 & 427 & $(42.4,54.0)$ & $(33.9,53.2)$ & 86.7 & 65.1 & 78.2 & 93.0 & 85.3 \\
\hline 1982 & 417 & $(43.5,54.5)$ & $(34.9,54.5)$ & 69.3 & 64.3 & 63.6 & 77.0 & 70.5 \\
\hline 1983 & 426 & $(52.8,39.2)$ & $(44.2,34.3)$ & 17.8 & 34.0 & 13.1 & 7.0 & 18.7 \\
\hline Average & & & & 62.6 & 56.9 & $\overline{57.9}$ & $\overline{45.2}$ & $\overline{48.7}$ \\
\hline Rank & & & & 1 & 3 & 2 & 5 & 4 \\
\hline
\end{tabular}

* 1: Rational choice of institutional arrangements.

2: Rational choice of budget size.

3: Rational choice of budget division.

4: Conventional wisdom: Party.

5: Conventional wisdom: Party-region. 
based: 1981. Unified Republicans coalesced with fiscally conservative Southern Democrats (Boll Weevils) to adopt the most dramatic reconciliation package in the four-year period. Accordingly, Hypotheses 4 and 5 correctly predict a high percentage of the votes-93.0 and 85.3, respectively. But inspection of the distribution of preferences in 1981 illustrates three less-obvious points. First, consistent with conventional wisdom, ideal points were such that the budget process resulted in a relatively small budget in 1981. Second, the data and theory suggest that the bulk of the reductions in expenditures should have occurred on the domestic dimension, which indeed they did. And third, although overshadowed by the performance of the party-based conventional wisdom hypothesis, Hypothesis 1 , nevertheless, scores an impressive 86.7 percent. Thus, the events of 1981, from which much conventional wisdom is derived, appear to have a theoretical basis.

The situation is similar in 1982. The distribution of ideal points is comparable in 1981 and 1982, as one would expect in the absence of an intervening election. Accordingly, the budget process equilibrium $(B)$ again produces a smaller budget than that for the appropriations process $(A)$. Notice, however, that the relative reduction comes at the expense of domestic spending; point $B$ is actually slightly greater on the military dimension. While we are reluctant to make too much of this difference, it, nevertheless, seems consistent with the final outcome of the 1982 budget process. Defense spending continued to increase significantly in spite of further cuts in domestic spending. ${ }^{11}$ Finally, as in 1981 each hypothesis predicts reasonably well, although not as well as in the previous year.

The combined analyses for 1981 and 1982 underscore the difficulties with selecting one hypothesis over another when they yield similar predictions. Such will be the case whenever Republicans are predominantly fiscally conservative, Democrats tend to be bigger spenders, and the condition of the theorem is not met. Thus, for a more convincing demonstration that theory is an improvement upon conventional wisdom, it would be useful to observe a year in which the configuration of preferences meets the condition stated in the theorem. Such a year is 1980 , although just barely. Here strict application of the budget process has the theoretical effect opposite that in 1982: to increase domestic spending, decrease defense spending, and increase (slightly) the size of the budget. Consequently, in 1980, Hypotheses 4 and 5 predict very poorly (3.8 and 20.1 percent, respectively). Democrats overwhelmingly favored a strict budget process in 1980 while Republicans opposed it.

${ }^{11}$ See Congressional Quarterly Almanac (1982, p. 195). 
FIGURE 6

Distribution of Ideal Points and Normalized Locations

of Equilibria, 1980-83*

1980

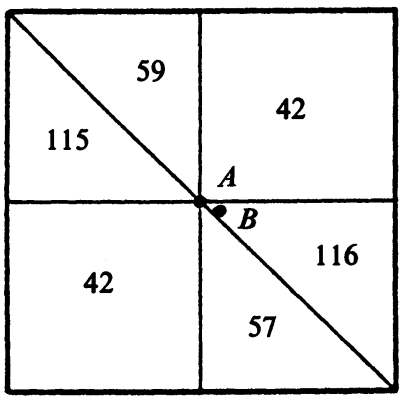

$B=(0.8,-.07)$

1982

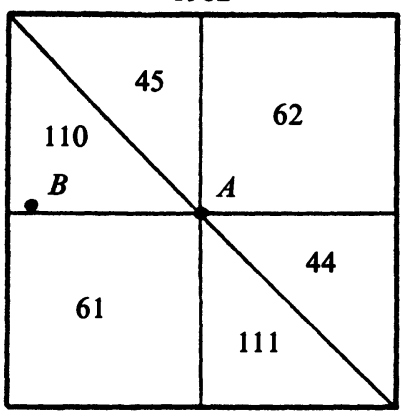

$B=(-8.6,0.02)$
1981

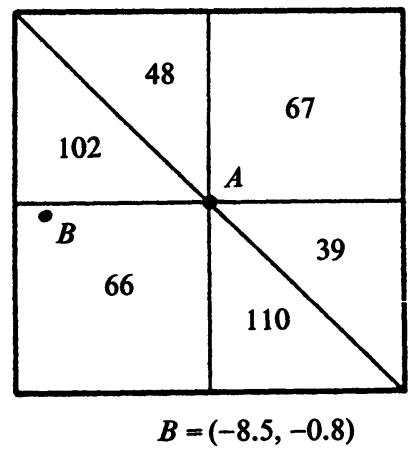

1983

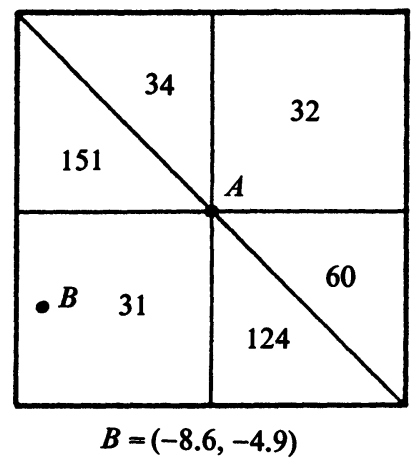

*The piecemeal appropriations equilibrium $(A)$ is always at the origin $(0,0)$. Numbers denote members whose ideal points were located in the given region.

Moreover, since the supporting Democrats tended to have ideal points in the prodomestic-antimilitary regions of the space, Hypotheses 1 and 3 predict well (76.5 and 76.7 percent, respectively). Still, given the closeness of the two equilibria in 1980 and the crudeness of our estimated ideal points, this support is qualified.

At this stage in the analysis, 1983 was expected to be a uniquely useful if not decisive year for the test. Interpretations of the 1982 election and of the subsequent 1983 budget process suggest that the configuration of preferences in 1983 would more closely approximate that of 
1980 than 1981 and 1982. Democrats gained 26 seats in the 1982 election by running against Reagan's domestic spending cuts. Republicans, meanwhile, stressed differences between their preferences and Reagan's policies and recession. Moreover, these apparent trends toward restoration of spending persisted into the budget cycle. The House's budget resolution, which called for a $\$ 33$ billion increase in domestic spending was dubbed the "Democratic Manifesto," and House Republicans went to extremes not to consider Reagan's budget, which called for further reductions in domestic spending. The Republican strategy was to seek a rule that would have permitted consideration of as many as 15 amendments, a la the piecemeal appropriations process. But the Democrats won the procedural battle in 1983, passing a modified closed rule. In practice, the rule was completely closed, since Republicans, not wanting to embarrass Reagan, declined to put forth a substitute.

The administration was similarly unenthusiastic about its prospects for a repeat performance of the budget process. The Congressional Quarterly Almanac called it an "ironic turnabout" that

the Reagan administration displayed growing disenchantment with the process which
the president had used as a vehicle for implementing his economic program in 1981 and
1982. As lawmakers whittled away at Reagan's proposed military spending increase,
Defense Secretary Caspar W. Weinberger suggested to the president that the adminis-
tration might be better off without a congressional budget. That way, Weinberger rea-
soned, Reagan might be able to get more money for defense in the appropriations pro-
cess, and he would be able to veto funding bills for other programs if he thought they
were too high. $(1983, \mathrm{p} .435)^{12}$

How might these perceptions and events be summarized in terms of the theory? Electoral outcomes suggest redistribution of ideal points from $S$ to $T$ (and perhaps from $Q$ to $P$ ) in the policy space, while Weinberger's strategy suggests that the appropriations process would have resulted in greater defense spending than would the budget process. Thus, the budget process equilibrium could be expected to be located east-southeast of the appropriations equilibrium - south if Weinberger's expectation of lower defense spending under the budget process were correct, and east if the strength of the Democrats were, in fact, based on a desire for restoration of domestic programs. The corresponding prediction of the theory is that such Democrats would succeed in using the budget process to bring about a relative increase in the size of the budget. However, as Figure 6 shows, not all of these changes are reflected in the data. The budget process indeed seems to have kept military expenditures relatively low (as

${ }^{12}$ See also Reischauer (1984, p. 409) and Fisher (1984, p. 417). 
Weinberger feared), and Democrats definitely supported protection of their resolution by passing the restrictive rule (see Table 1, Hypothesis 4). But because the expected easterly shift of $B$ relative to $A$ did not occur, all five hypotheses predict poorly in 1983 .

The results from 1983 raise the awkward question of whether the theory or the data are suspect. While ultimately the reader should make this judgment, presently we cannot deny that our prediction is poor in 1983. We can merely point to assorted electoral facts, legislative strategies, and administrative statements that seem more consistent with the theory than with the data. In contrast, it is not possible to explain away the failure of the conventional wisdom hypotheses in 1983 (nor in 1980). Indisputably, Republicans sometimes oppose strict application of the new budget process.

In sum, the empirical analysis yields one confident and two tentative findings. The confident finding is the considerable direct evidence against hypotheses based on conventional notions of party and region. The tentative findings include some direct evidence for the hypothesis of rational choice of institutional arrangements and thus some indirect evidence for our institution- and preference-based theory of congressional budgeting.

\section{Discussion}

The theory of congressional budgeting was developed and tested in the context of a simple two-dimensional policy space and under some rather strong assumptions. The choice of simplicity over complexity was dictated by a strong desire to test the theory, even if only indirectly. This discussion notes some possible theoretical modifications and places the results in the context of prior studies of the budget process.

The two assumptions that are perhaps most objectionable are circular preferences and the number of issues. The number of issues under consideration is not essential to the formal argument. Attention was restricted to two issues-domestic and military spending-only to facilitate exposition, to maintain a resemblance between the theory and actual congressional budgetary politics, and to perform a test. In principle (if not in practice), the theoretical results can be extended and applied to a world with, say, 13 appropriations bills, in which case the appropriations and budget process equilibria still could be derived. Similarly, the distributional conditions for the budget process resulting in a larger budget could be determined. But the calculations would be more complicated, and the conditions for different budget sizes under different institutional arrangements would be difficult to interpret. Furthermore, the argument that members possess sufficient information about preferences to behave in a fully sophisticated manner may be more difficult to sustain. 
A second possible theoretical modification is to relax the assumption on preferences from circularity to strict convexity. Then it would remain true that every one-dimensional subset of the space has a unique majority rule equilibrium; however, the location of the new equilibrium would depend on the order in which appropriations bills arise. This raises two problems. First, because there would be several different order-dependent equilibria for each process, it would be difficult to assess the effect of changing from one institution to another. Second, if members did not know the order in which the appropriations bills were to be decided, their calculations of voting strategies would not be straightforward. In essence, equilibria would still exist, but in the absence of imposing some additional structure on the problem (such as a specified order of voting on appropriations), it seems unlikely that members of Congress would behave such that the equilibria were obtained.

There are two ways of addressing this situation, although neither is completely satisfactory. It could be assumed that members know the order in which bills are considered and that the order is the same with or without the new budget process. But historically the ordering of congressional appropriations bills is erratic. An alternative assumption is that members believe that each order was equally probable and that at each stage they calculated the consequences of their decisions accordingly. The consequences of this modification are unclear.

In light of these difficulties, and for the reasons specified in footnote 8 , the assumption of circular indifference curves was employed rather than a known order of voting. Under these conditions the order of consideration of bills is not essential to the principal theoretical result. The equilibrium under the budget process is positive with respect to the appropriations equilibrium if and only if a majority prefers to move in a budget-increasing direction (or, technically, that a majority of members have gradients in $P, U$, or $T$, as illustrated in Figure 4).

While not overwhelming, the empirical support for the theory is reasonably strong, given that the theory is motivated by individuals' preferences and that good measures of such preferences are difficult to devise. Naturally, advocates of various emerging techniques (see fn. 10) are invited to reassess these results using the method of their choice. As noted earlier, our choice was shaped by a desire for simplicity.

With these qualifications and insofar as the failure of the conventional wisdom hypotheses is convincing, the contrasting inability to reject the hypothesis derived from this new theory of the budget process must be interpreted as supportive. We hasten to add, however, that by rejecting party- and region-based accounts of voting, we are not maintaining that party and region are unimportant in congressional budgeting. 
To the contrary, major roll call votes on the floor during the budget process are almost invariably partisan, and significant deviations from partisan votes are often associated with region, especially in the 1980 s and in the House. Nevertheless, the temptation to respond to these empirical regularities by embracing party and region as explanations for congressional behavior should be avoided because, in the absence of additional information, the associated predictions are vacuous. In the case of choosing budgetary institutional arrangements, for example, a prediction that a member votes with his/her party (or region) says nothing explicit about why he/she does so, nor does it say how other members of his/her party (or region) vote. The key points are that the party and region variables are proxies for preferences and that such preferences-when combined with members' expectations about how institutions work-are the real predictors of congressional behavior in the budget process.

Not all of these ideas are new. Students of electoral behavior are undoubtedly familiar with the argument that the party variable is a proxy for preferences (Page and Jones, 1979; Fiorina, 1981; Rivers, 1981), and more recently the same observation has been transported to congressional budgeting (West, 1985). Similarly, the combined effects of preferences and institutions are prevalent in two bodies of the congressional literature. Most obvious of these are theoretical studies that identify "structure-induced equilibria" (Shepsle, 1979, 1986; Shepsle and Weingast, forthcoming; Denzau and Mackay, 1983; Krehbiel, forthcoming). Empirical studies are also implicitly consistent with the combined focus on preferences and institutions. For example, historical studies of how congressional electoral outcomes are translated into policy outcomes identify changes in members' preferences and occasional calculated changes in internal institutional features as key causes (Brady, 1985; Brady and Morgan, 1986; Stewart, 1985). And more recent topics include how electoral incentives of members of Congress affect budget outcomes, and how the presidential veto and budgetary reversion points help predict appropriations outcomes (Kiewiet and McCubbins, 1985, 1986).

While consistent with several prior studies, this research uniquely introduces a testable individual-level theory of the congressional budget process. To the question of whether a strict budget process reduces the size of the budget relative to a piecemeal appropriations process, the theoretical answer of "not necessarily" is ostensibly equivocal. But fortunately the theory specifies the precise conditions and has testable implications. If the data are convincing, then the answer to the parallel empirical questionwhether the budget process in practice has reduced the size of the budget relative to alternative arrangements-is almost surely "yes" for the early 
$1980 \mathrm{~s} .{ }^{13}$ Critics of the new congressional budget process may doubt that things would have been "worse" in its absence, but our primary focus and findings are somewhat broader. We are persuaded by and more generally have corroborated Ellwood's (1984) argument that the effect of reconciliation on budget sizes is "neutral on its face." So too is the new budget process. But additionally, this study demonstrates why the institutional story is not the whole story, neither in theory nor in practice. In practice, individual preferences temper the theoretical neutrality of institutions. Thus, the thesis that preferences and institutions "conspire" to produce structure-induced equilibria (Shepsle, 1979) takes on a more concrete meaning in the context of congressional budgeting. The coconspirators in congressional budgetary outcomes are preferences of individual members regarding spending and their ability to choose institutional arrangements.

\section{Manuscript submitted 10 September 1985 \\ Final manuscript received 16 May 1986}

\section{APPENDIX}

Votes

In 1980 the key vote (no. 456) was on the rule that would govern debate on the reconciliation bill, HR 7765. The modified closed rule, H.Res. 776, would have permitted only "technical amendments" (Congressional Quarterly Almanac, 1980, p. 128). The decisive vote came on Rules Committee Chairman Richard Bolling's motion for the previous question which in effect blocked amendments on the rule (and in turn blocked all controversial amendments from the bill). A yea vote, therefore, is interpreted as supportive of a strict budget process. Conversely, a nay vote would have resulted in attempts to amend the rule, namely by allowing for greater amendments on the bill to which it pertained. Ultimately, a more open rule would have resulted in decision making that approximated an appropriations process. But the relatively closed procedure was adopted in a 250-157 vote. (Alternatively $y_{2}$ the earlier vote on an amendment to remove the reconciliation instructions from the first resolution could have been used. The later vote on the rule for the reconciliation bill was selected because ultimately the restrictive rule was necessary for the 1980 process to approximate our model of the budget process.)

In preparation for debate on the 1981 reconciliation bill, Democrats wrote a rule for floor debate under which members would vote separately on spending cuts included in the bill (and supported by the administration). Had it passed, the binding effect of the first budget resolution would have been undermined, whereas under the procedure favored by the Republicans and conservative Democrats a single up-or-down vote was taken on the Gramm-Latta package. Vote number 95 was the main procedural vote (Congressional Quarterly Almanac, 1981, p. 262). The motion was rejected 210-217.

There was no comparable controversy over rules in 1982, although there was a dispute during consideration of the first budget resolution that determined how rigidly the expenditure levels would be enforced. To each of three substitutes to the resolution,

${ }^{13}$ Of the possible exceptions, 1983 is questionable, and 1980 appears to have been a year in which the budget-increasing effect of a relatively strict budget process was minimal. 
Appropriations Committee Chairman Jamie Whitten proposed amendments that called for the removal of deferred enrollment. Deferred enrollment is a provision that requires any appropriation that exceeds the budget ceiling (established by the resolution) to be kept from going to the president (see Fisher, 1985, pp. 9-10). Whitten's proposed removal of the provision, therefore, would have made it possible for appropriations to exceed the ceiling established by the resolution, which of course is contrary to a budget process in which the resolution is genuinely binding. Roll call votes were taken on only two of his three amendments, and the analysis reported is of the first vote (no. 119). A vote against the amendment is interpreted as support for the budget process (Congressional Quarterly Almanac, 1982, pp. 194-95). The amendment was adopted 212-205.

The main procedural vote in 1983 was on the Democratic rule to the first budget resolution (no. 38). The rule permitted only one Republican substitute to the Budget Committee's resolution which otherwise was protected from amendments. A vote in favor of the modified closed rule is interpreted as support for the budget process, since the resolution contained reconciliation instructions and provisions for making the spending ceilings of the first resolution binding if a second resolution were not passed. The vote was 230 for and 187 against (Congressional Quarterly Almanac, 1983, p. 437).

(For all roll calls, pairs and announcements were coded as if they were votes.)

\section{REFERENCES}

Bozeman, Barry, and Jeffrey D. Straussman. 1982. Shrinking budgets and the shrinkage of budget theory. Public Administration Review, 42:509-15.

Brady, David. 1985. A reevaluation of realignments in American politics: Evidence from the House of Representatives. American Political Science Review, 79:28-49.

- and Mark A. Morgan. 1986. Reforming the structure of the House appropriations process: The effects of the 1885 and 1919-20 reforms on money decisions. In Mathew McCubbins and Terry Sullivan, eds., Congress: Structure and policy. New York: Cambridge University Press.

Carson, Richard T., and Joe A. Oppenheimer. 1984. A method of estimating the personal ideology of political representatives. American Political Science Review, 78:163-78.

Collender, Stanley E. 1983. The guide to the federal budget. Washington, DC: Urban Institute.

Copeland, Gary W. 1983. Changes in the House of Representatives after the passage of the budget act of 1974. In W. Thomas Wander, F. Ted Hebert, and Gary W. Copeland, eds., Congressional budgeting: Politics, process, and power. Baltimore: Johns Hopkins University Press.

Denzau, Arthur T., and Robert J. Mackay. 1983. Gatekeeping and monopoly power of committees: An analysis of sincere and sophisticated behavior. American Journal of Political Science, 27:740-61.

Ellwood, John W. 1983. Budget control in a redistributive environment. In Allen Schick, ed., Making economic policy in Congress. Washington, DC: American Enterprise Institute.

- 1984. Comments on Shepsle and Weingast's "Legislative politics and budget outcomes." In Gregory B. Mills and John L. Palmer, eds., Federal budget policy in the 1980s. Washington, DC: Urban Institute.

Fiorina, Morris P. 1981. Retrospective voting in American national elections. New Haven: Yale University Press.

Fisher, Louis. 1983. The budget act of 1974: A further loss of spending. In W. Thomas Wander, F. Ted Hebert, and Gary W. Copeland, eds., Congressional budgeting: Politics, process, and power. Baltimore: Johns Hopkins University Press.

-1985. The budget act of 1974: Reflections after ten years. Presented at the annual meeting of the Midwest Political Science Association. 
Gilmour, John B. 1985. Political consequences of the congressional budget process. Presented at the annual meeting of the Midwest Political Science Association.

Kalt, Joseph P., and Mark A. Zupan. 1984. The ideological behavior of legislators: Rational on-the-job consumption or just a residual? Discussion paper. Cambridge: Harvard Institute of Economic Research.

Kau, James B., and Paul H. Rubin. 1979. Self-interest, ideology, and logrolling in congressional voting. Journal of Law and Economics, 22:365-84.

Kiewiet, D. Roderick, and Mathew McCubbins. 1985. Congressional appropriations and the electoral connection. Journal of Politics, 47:59-82.

- 1986. Presidential influence on congressional appropriations decisions. Manuscript. California Institute of Technology.

Kramer, Gerald H. 1972. Sophisticated voting over multidimensional choice spaces. Journal of Mathematical Sociology, 2:165-80.

Krehbiel, Keith. Forthcoming. Sophisticated committees and structure-induced equilibria in Congress. In Mathew McCubbins and Terry Sullivan, eds., Congress: Structure and policy. New York: Cambridge University Press.

LeLoup, Lance T. 1980. The fiscal Congress. Westport, CT: Greenwood Press.

- 1982. After the blitz: Reagan and the U.S. congressional budget process. Legislative Studies Quarterly, 7:321-40.

Miller, James A., and James D. Range. 1983. Reconciling an irreconcilable budget. Harvard Journal on Legislation, 20, 4:4-30.

Page, Benjamin I., and Calvin Jones. 1979. Reciprocal effects of party preferences, party loyalties, and the vote. American Political Science Review, 73:1071-89.

Poole, Keith T. 1981. Dimensions of interest group evaluation of the U.S. Senate, 19691978. American Journal of Political Science, 25:49-67.

Reischauer, Robert D. 1984. The congressional budget process. In Gregory B. Mills and James L. Palmer, eds., Federal budget policy in the 1980s. Washington, DC: Urban Institute.

Rivers, Douglas. 1981. The dynamics of party support in the American electorate, 19521978. Ph.D. diss., Harvard University.

Schick, Allen. 1980. Congress and money. Washington, DC: Urban Institute.

- 1981. Reconciliation and the congressional budget process. Washington, DC: American Enterprise Institute.

Shepsle, Kenneth A. 1979. Institutional arrangements and equilibrium in multidimensional voting models. American Journal of Political Science, 23:27-60.

- 1984. The congressional budget process: Diagnosis, prescription, prognosis. In W. Thomas Wander, F. Ted Hebert, and Gary W. Copeland, eds., Congressional budgeting: Politics, process, and power. Baltimore: Johns Hopkins University Press.

- 1986. The positive theory of legislative institutions: An enrichment of social choice and spatial models. Public Choice, 50:135-78.

- and Barry R. Weingast. Forthcoming. The institutional foundations of committee power. Forthcoming, American Political Science Review.

Stewart, Charles. 1985. Does structure matter? The effects of decentralization in the House on spending. Presented at the annual meeting of the Midwest Political Science Association.

Wander, W. Thomas. 1984. The politics of congressional budget reform. In W. Thomas Wander, F. Ted Hebert, and Gary W. Copeland, eds., Congressional budgeting: Politics, process, and power. Baltimore: Johns Hopkins University Press.

West, Darell M. 1985. Congressional decision-making and the Reagan economic program. Presented at the annual meeting of the Midwest Political Science Association. 